\title{
ASSOCIATION OF OBESITY WITH RS1421085 AND RS9939609 POLYMORPHISMS OF FTO GENE WITH T2DM IN EGYPTIAN FEMALES
}

\author{
ADEL A. H. ABDEL RAHMAN, AHMED E. S. ABDEL MEGIED, RIZK A. EL BAZ², ALAA M. WAFA², ABEER S. EL \\ ZEKRED* $^{*}$
}

${ }^{1}$ Faculty of Science, Menoufia University, Egypt, ${ }^{2}$ Faculty of Medicine, Mansoura University, Egypt

Email: hendmarkeg@yahoo.com

Received: 23 Sep 2018 Revised and Accepted: 04 Aug 2018

\begin{abstract}
Objective: Obesity has been described as a worldwide increasing health problem and risk factor of various disorders including type 2 diabetes mellitus (T2DM). So, our study aim to determine of common variants of fat mass and obesity associated gene polymorphisms rs1421085 and rs
\end{abstract} 9939609; confers risk of obesity and type 2 diabetic mellitus in Egyptian females.

Methods: In this population rs1421085 and rs9939609 polymorphisms of fat mass and obesity (FTO) gene were genotyped in 105 obese patients and 100 healthy controls with ages 14-60 y were collected from Medicine Specialized Hospital, Mansoura University, Egypt during the period between Jul.-Oct. 2016, genotyping of SNPs was performed by restriction fragment length polymorphism (RFLP) assay, fasting blood glucose, homeostasis model assessment of insulin resistance (HOMA IR), body mass index (BMI), waist-to-hip ratio (WHR) lipid profile was determined.

Results: There was the significantly higher frequency of the AA compared to controls $p=0.0001$ ) of genotypers 9939609 . Also, cases have shown a significantly higher frequency of the $\mathrm{C}$ allele, $\mathrm{p}<0.00001$ ) of rs1421085 genotype polymorphisms increased the risks of obesity. On the other hand, there were no significant correlations between genotypes and obesity-related (anthropometric body composition) parameters. Only the fasting blood glucose was significantly higher in the $\mathrm{TA} p=0.004)$.

Conclusion: The FTO rs9939609 and rs1421085 single nucleotide polymorphisms (SNPs) was associated with increased risk of obesity in type 2 diabetic populations on Egyptian females.

Keywords: FTO, Polymorphism, Obesity, BMI, Body fat

(C) 2018 The Authors. Published by Innovare Academic Sciences Pvt Ltd. This is an open access article under the CC BY license (http://creativecommons.org/licenses/by/4.0/) DOI: http://dx.doi.org/10.22159/ijpps.2018v10i9.22747

\section{INTRODUCTION}

FTO gene was assigned to chromosome 16 at position 12.2 [1]. FTO has a total length of $410509 \mathrm{bp}$ and contains nine exons and several nucleotide polymorphisms [2]

The fact that high levels of FTO expression are found in the brain, specifically in the accurate nucleus of the hypothalamus, which is known to play a major role in controlling energy homeostasis and eating behaviour, together with new insights from recent in vitro studies indicating a possible role in energy expenditure, provides support for a role of FTO in the explanation of obesity development [3, 4].

Obesity is considered a medical condition involving an accumulation of excess body fat potentially posing a threat to health and life of an individual. The prevalence of obesity is increasing worldwide in both developing and developed countries. It has become a serious epidemic health problem, estimated to be the fifth leading cause of modality at global level [5-9]. On the other hand, studies in Chinese Han [10], Oceanic [11], and African populations [12] failed to confirm rs9939609 variant as a major contributor to obesity and type 2 diabetic (T2D). Studies in Korean, Malay, Japanese, Canadians of South Asian origin, and Chinese populations have reported the association of this SNP with BMI and obesity [13-19]. Despite less frequency of risk allele A in the Chinese population, its effect on BMI was the same as that in the European population [13]. FTO variant associated strongly with T2D but weakly with obesity in Indians [20]. In short, the disease association of the FTO variant varies with ethnicity and populations.

To determine whether FTO gene is a genetic risk factor for developing obesity in Egyptian females, we analyzed rs1421085 and rs9939609 polymorphisms in patients with T2DM, diabetic obesity and healthy controls. Besides, the relationship between FTO gene polymorphisms and obesity is discussed in the manuscript.

\section{MATERIALS AND METHODS}

\section{Limitation of the study}

This work based on 105 cases (after taking their approved) representing obeses cases and obese diabetic cases; 55 cases obese only. Their mean age \pm SD $36.07 \pm 10$, range of $14-61$ y and 50 cases presenting diabetic obeses with mean age \pm SD $38.94 \pm 11$ and comparing with 100 healthy control are collecting from the central area of Nile Delta of Egypt from the Department Obesity and Diabetes International Medicine Specialized Hospital, Mansoura University, Egypt, and comparing cases to their complication with length, weight, cholesterol triglycerides, low density liprotien (LDL), high density liprotien (HDL), glycated homoglopein average of plasma glucose concentration (HbA1c), fasting blood glucose (FBG), Insulin, Homa IR, BMI. For all cases and controls; DNA extraction was carried out followed by PCR detection of their rs 1421085 and 9939609 genetic polymorphism.

\section{Measurement of anthropometric parameters}

Body weight, height, waist and hip circumference, systolic blood pressure (SBP), and diastolic blood pressure (DBP) were measured according to the standard procedures [21]. Body height was measured using a wall-mounted stadiometer, and body weight was measured using a digital scale. BMI of each subject was calculated. Waist circumference was measured just above navel midway between the lower margin of the last rib and iliac crest to the nearest $0.1 \mathrm{~cm}$. Hip circumference was taken as the maximal circumference over the buttocks. Waist-to-hip ratio was calculated from the values of waist and hip circumference. DBP was measured twice from the right arm of the subject in a sitting position using a standard mercury sphygmomanometer.

\section{Measurement of metabolic parameters}

Blood samples were drawn after an overnight fast of 8-12 h. Fasting blood glucose (FBG) levels were determined by the glucose oxidase 
method using HumaStar 180 chemistry analyzer (Human, Wiesbaden, Germany). Concentrations of plasma insulin, leptin, and leptin receptors were determined by ELISA using the commercial kit with an automated EIA analyzer (Bio-Rad Laboratories, Hercules, CA, USA). FBG and fasting insulin levels were used to measure homeostasis model assessment of insulin resistance (HOMA-IR) calculated by the following formula: HOMA-IR = Fasting insulin $(\mu \mathrm{IU} / \mathrm{ml}) \times$ Fasting glucose $(\mathrm{mmol} / \mathrm{l}) / 22.5[22]$.

\section{DNA extraction and genotyping}

Genomic DNA was extracted from whole blood using genomic DNA purification kit (Fermentas, USA). Genotyping of rs9939609 polymorphism at FTO locus was carried out by polymer as a chain reaction-restriction fragment length polymorphism assay (PCR-RFLP). A DNA fragment containing rs9939609 polymorphism was amplified using specific primers (forward primer sequence: AACTGGCTCTTGAATGAAATAGGATTCAGA and reverse primer sequence: AGAGTAACAGAGACTATCCAAGTGCAGTAC). The PCR was carried out using thermocycler (Icycler 5, BioRad, USA) according to the optimized conditions. In $25 \mu \mathrm{L}$ reaction, PCR components comprised of $50 \mathrm{ng}$ DNA, 1X Taq buffer, $2 \mathrm{mmol} \mathrm{MgCl} 2,200 \mu \mathrm{M}$ of each dNTP, $10 \rho \mathrm{mol}$ of each primer, and 1U Taq DNA polymerase. Thermal cycling was performed as follows: initial denaturation at $95^{\circ} \mathrm{C}$ for 4 min, followed by 35 cycles of denaturation at $94{ }^{\circ} \mathrm{C}$ for $30 \mathrm{sec}$, annealing at $58{ }^{\circ} \mathrm{C}$ for $30 \mathrm{sec}$ and extension at $72{ }^{\circ} \mathrm{C}$ for $1 \mathrm{~min}$, and then a final extension step at $72^{\circ} \mathrm{C}$ for $10 \mathrm{~min}$. Amplified products were digested with Sca1 restriction enzyme (Favorgen, Taiwan) to analyze for polymorphism by RFLP assay polymorphisms of primers of the rs $1421085 \mathrm{~T}>\mathrm{C}$ polymorphism were 5GGCAGACTTGTAAGGAACAAGA-3 (forward) and 5-AAATTCT-CATCAGACACTTAATCGAT-3 (reverse) which generated the 127-bp fragment. For the rs1421085 $\mathrm{T}>\mathrm{C}$ variant, the expected fragment sizes were 101-and 26-bp for the ECO32I restriction site. The PCR profile for the rs 1421085 $\mathrm{T}>\mathrm{C}$ polymorphism consisted of an initial melting step of $95^{\circ} \mathrm{C}$ for $5 \mathrm{~min}$; 35 cycles of $95^{\circ} \mathrm{C}$ for $30 \mathrm{~s}, 51^{\circ} \mathrm{C}$ for $40 \mathrm{~s}$ and $72^{\circ} \mathrm{C}$ for 40 s and a final step of $72^{\circ} \mathrm{C}$ for $10 \mathrm{~min}$.

\section{Statistical analysis}

The data were analyzed using Statistical Package for Social Sciences (SPSS Inc. Chicago, IL, USA, version 17.0). Quantitative variables were expressed as mean \pm standard error (SE). Student's $t$-test was applied to observe the differences between case and control groups. The whole data were stratified according to age in subgroups. Hardy Weinberg equilibrium test (HWE) was applied to determine the variation in distribution of alleles and genotypes within the concerned population. Allelic frequencies were calculated by gene counting. Chi-square $\left(\chi^{2}\right)$ test was used to determine the significant differences of genotype and allelic frequencies between obese and nonobese groups. Association of rs9939609 and the rs1421085variant with obesity was determined by Pearson Chisquare using codominant, dominant and recessive models. Odds ratio (OR) and 95\% confidence interval (CI) were calculated to determine the risk of obesity associated with the risk allele. The association of FTO rs9939609 variant with anthropometric and metabolic traits was determined using General Linear Model (GLM) assuming codominant, dominant, and recessive genetic models. The genotypes were coded as $(0,1,2)$ in codominant model, $(0,1)$ in dominant model and $(1,0)$ in recessive model corresponding to the number of copies of risk allele.

\section{RESULTS}

By comparing demographic and laboratory data of obese cases compared to controls (table 1) shows demographic and laboratory data of obese cases compared to controls. All parameters showed significant higher values in cases compared to controls $(p<0.05)$ except for the waist hip ratio (WHR). On the other hand, the demographic and laboratory data of obese diabetic cases compared to controls (table 1) shows demographic and laboratory data of obese diabetic cases compared to controls. All parameters showed significant higher values in cases compared to controls $(\mathrm{p}<0.05)$ except for the waist-hip ratio and LDL levels ( $p>0.05$ ).

The demographic and laboratory data of obese non-diabetic cases compared to controls shows demographic and laboratory data of obese non-diabetic cases compared to controls. Values corresponding to length, weight, cholesterol, triglycerides, LDL, insulin, Homa IR, waist, hip and BMI were significantly higher in cases compared to controls $(\mathrm{p}<0.05)$; whereas both groups showed no significant difference regarding their age, waist-hip ratio, FBG and $\mathrm{HbA1C}(\mathrm{p}>0.05)$.

Table 1: Demographic and laboratory data of obese and obese diabetic cases compared to controls

\begin{tabular}{|c|c|c|c|c|c|c|c|c|}
\hline & \multicolumn{2}{|c|}{ Controls $^{+}$} & \multicolumn{3}{|c|}{ Obese $^{++}$} & \multicolumn{3}{|c|}{ Obese Diabetic $^{+++}$} \\
\hline & Mean & \pm SD & Mean & \pm SD & $\mathbf{p}$ & Mean & \pm SD & $\mathbf{p}$ \\
\hline Age & 31.88 & 11.066 & 36.07 & 10.870 & $.007 *$ & 38.94 & 11.083 & $.000^{* *}$ \\
\hline Length & 165.14 & 10.956 & 159.38 & 6.077 & $.000^{* *}$ & 158.36 & 7.631 & $.000^{* *}$ \\
\hline Weight & 72.20 & 56.719 & 105.47 & 13.024 & $.000^{* *}$ & 108.20 & 9.282 & $.000^{* *}$ \\
\hline Cholesterol & 171.98 & 12.367 & 202.71 & 43.770 & $.000 * *$ & 202.18 & 41.621 & $.000^{* *}$ \\
\hline Triglyceride & 82.12 & 20.873 & 137.33 & 52.406 & $.000^{* *}$ & 151.40 & 47.398 & $.000^{* *}$ \\
\hline HDL & 41.64 & 5.268 & 44.43 & 12.413 & $.039 *$ & 49.66 & 14.349 & $.000^{* *}$ \\
\hline LDL & 119.70 & 19.414 & 133.77 & 42.481 & $.003^{*}$ & 120.99 & 39.190 & .787 \\
\hline $\mathrm{HbA1c}$ & 5.10 & .518 & 7.15 & 4.931 & $.000^{* *}$ & 8.05 & 1.515 & $.000^{* *}$ \\
\hline FBG & 95.43 & 7.175 & 119.44 & 32.136 & $.000^{* *}$ & 146.56 & 26.038 & $.000^{* *}$ \\
\hline Insulin & 5.42 & 1.585 & 22.39 & 4.627 & $.000^{* *}$ & 19.95 & 4.942 & $.000^{* *}$ \\
\hline Homa IR & 1.15 & .390 & 5.73 & 1.127 & $.000 * *$ & 6.35 & 1.239 & $.000^{* *}$ \\
\hline Waist & 66.04 & 9.147 & 102.48 & 7.941 & $.000^{* *}$ & 103.68 & 6.747 & $.000^{* *}$ \\
\hline Hip & 79.04 & 8.888 & 112.29 & 8.092 & $.000^{* *}$ & 113.72 & 6.725 & $.000^{* *}$ \\
\hline WHR & .95 & 1.169 & .91 & .014 & .717 & .91 & .006 & .798 \\
\hline $\mathrm{BMI}^{* * *}$ & 24.32 & 1.606 & 41.66 & 5.739 & $.000^{* *}$ & 43.42 & 5.639 & $.000 * *$ \\
\hline
\end{tabular}

${ }^{+} n=100,{ }^{+} n=55,{ }^{++} n=50,{ }^{*}=$ p-value $<0.05,{ }^{* *}=$ p-value $<0.001,{ }^{* * *}$ BMI: body mass index (\%). Data presented mean \pm SD.

The frequency of FTO rs9939609 polymorphic forms in total obese cases compared to controls adjusted by age (table 2) shows the frequency of FTO rs9939609 polymorphic genotypes in total obese cases compared to controls adjusted by age. Obese cases showed significantly higher frequency of the AA genotype compared to controls in the codominant model $(21.9 \%$ vs. $4 \%, \mathrm{p}=0.0001)$. Also, observed in the recessive model $(\mathrm{p}=0.0001)$. However, cases showed a significantly lower frequency of TA genotype in the overdominant model $(35.2 \%$ vs. $60 \%$, $\mathrm{p}=0.00026)$.
The Frequency of FT0 rs9939609 polymorphic forms in total obese cases compared to controls adjusted by diabetes and age (table 2) shows the frequency of FTO rs9939609 polymorphic genotypes in total obese cases compared to controls adjusted by age and diabetes. Obese cases still, showed significantly higher frequency of the AA genotype compared to controls in the codominant model $(21.9 \%$ vs. $4 \%, \mathrm{p}=0.012)$. This was also observed in the recessive model ( $\mathrm{p}=0.0039)$.

The results of FTO rs9939609 exact test for Hardy-Weinberg equilibrium shows exact test for Hardy-Weinberg equilibrium in 
all studied subjects as well as each separate group. Regarding the groups of all participants, the test showed the non-significant difference between the observed and expected frequencies for polymorphic genotypes i.e. coping with the genetic equilibrium.
On the contrary, regarding each individual group of controls and cases, each was significantly departing from the equilibrium probably due to the high values of AA in cases and TA in controls.

Table 2: Frequency of FTO rs 9939609 polymorphic forms in total obese cases compared to controls adjusted by diabetes and age

\begin{tabular}{|c|c|c|c|c|c|c|c|}
\hline \multirow[t]{2}{*}{ Model } & \multirow[t]{2}{*}{ Genotype } & \multirow[t]{2}{*}{ Controls $^{+}$} & \multirow[t]{2}{*}{ Obese } & \multicolumn{2}{|l|}{ Obese cases $^{++}$} & \multicolumn{2}{|c|}{ Obese-diabetic cases $^{+++}$} \\
\hline & & & & OR (95\% CI) & p-value & OR (95\% CI) & p-value \\
\hline \multirow[t]{3}{*}{ Codominant } & $\mathrm{T} / \mathrm{T}$ & $36(36 \%)$ & $45(42.9 \%)$ & 1.00 & $0.0001^{* *}$ & 1.00 & $0.0001^{* *}$ \\
\hline & $\mathrm{T} / \mathrm{A}$ & $60(60 \%)$ & $37(35.2 \%)$ & $0.58(0.31-1.07)$ & & $0.58(0.31-1.07)$ & \\
\hline & $\mathrm{A} / \mathrm{A}$ & $4(4 \%)$ & $23(21.9 \%)$ & $4.99(1.55-16.06)$ & & $4.99(1.55-16.06)$ & \\
\hline \multirow[t]{2}{*}{ Dominant } & $\mathrm{T} / \mathrm{T}$ & $36(36 \%)$ & $45(42.9 \%)$ & 1.00 & 0.65 & 1.00 & 0.65 \\
\hline & $\mathrm{T} / \mathrm{A}-\mathrm{A} / \mathrm{A}$ & $64(64 \%)$ & $60(57.1 \%)$ & $0.87(0.49-1.57)$ & & $0.87(0.49-1.57)$ & \\
\hline \multirow[t]{2}{*}{ Recessive } & $\mathrm{T} / \mathrm{T}-\mathrm{T} / \mathrm{A}$ & $96(96 \%)$ & $82(78.1 \%)$ & 1.00 & $0.0001^{* *}$ & 1.00 & $0.0001^{* *}$ \\
\hline & $\mathrm{A} / \mathrm{A}$ & $4(4 \%)$ & $23(21.9 \%)$ & $6.80(2.22-20.90)$ & & $6.80(2.22-20.90)$ & \\
\hline \multirow[t]{2}{*}{ Over dominant } & $\mathrm{T} / \mathrm{T}-\mathrm{A} / \mathrm{A}$ & $40(40 \%)$ & $68(64.8 \%)$ & 1.00 & $0.0026^{*}$ & 1.00 & $0.0026^{*}$ \\
\hline & $\mathrm{T} / \mathrm{A}$ & $60(60 \%)$ & $37(35.2 \%)$ & $0.41(0.23-0.74)$ & & $0.41(0.23-0.74)$ & \\
\hline \multirow[t]{2}{*}{ Alleles } & $\mathrm{T}$ & $132(66 \%)$ & $127(60 \%)$ & $1.27(0.8-1.9)$ & 0.29 & $1.27(0.8-1.9)$ & 0.29 \\
\hline & $\mathrm{A}$ & $68(34 \%)$ & $83(40 \%)$ & & & & \\
\hline
\end{tabular}

${ }^{+} \mathrm{n}=100,{ }^{+} \mathrm{n}=55$ and $+^{++} \mathrm{n}=50$.

On the other hand, the frequency of FTO rs1421085 polymorphic genotypes in total obese cases compared to controls adjusted by age shows the frequency of FTO rs1421085 polymorphic genotypes in total obese cases compared to controls adjusted by age. Obese cases showed significantly higher frequency of the CC genotype compared to controls (29.5\% vs. 3\%, $\mathrm{p}<=0.0001)$. This was also observed but to a lesser degree for the CT genotype $(37.1 \%$ vs. $29 \%, 4.89, \mathrm{p}=0.0001)$ in the codominant model. This was also observed in the recessive model for the CC genotype $(p=0.0001)$ and in the dominant model for the CT+CC genotypes $(66.7 \%$ vs. $32 \%, \mathrm{p}=0.0001)$. Cases have also shown a significantly higher frequency of the $\mathrm{C}$ allele $(48 \% v s .18 \%, \mathrm{OR}=4.37$, 95\% $\mathrm{CI}=2.8-6.8, \mathrm{p}<0.00001$ ).

The Frequency of FTO rs1421085 polymorphic forms in total obese cases compared to controls adjusted by diabetes and age shows the frequency of FTO rs1421085 polymorphic genotypes in total obese cases compared to controls adjusted by age and diabetes. Obese cases showed significantly higher frequency of the CC genotype compared to controls (29.5\% vs. 3\%, p<=0.0001). This was also observed but to a lesser degree for the CT genotype $(37.1 \%$ vs. $29 \%, \mathrm{p}=0.0001)$ in the codominant model. The same was also observed in the recessive model for the CC genotype $(\mathrm{p}=0.0001)$ and in the dominant model for the $\mathrm{CT}+\mathrm{CC}$ genotypes $(66.7 \%$ vs. $32 \%, \mathrm{p}=0.0001)$. Cases have also shown a significantly higher frequency of the C allele ( $48 \%$ vs. $18, \mathrm{p}<0.00001)$.
Hardy-Weinberg equilibrium in all studied subjects as well as each separate group, regarding the control group, the test showed nonsignificant difference between the rs1421085 exact tests for HardyWeinberg equilibrium shows exact test for observed and expected frequencies for polymorphic genotypes i.e. coping with the genetic equilibrium. On the contrary, regarding the group of cases and in all participants, the test was significantly departing from the equilibrium probably due to the high values of CC and CT in cases.

Significantly, higher frequency of the FTO rs9939609 A and rs1421085 C haplotype compared to controls $(22.1 \%$ vs. $6.11 \%$, $\mathrm{OR}=4.40,95 \% \mathrm{CI}=2.09-9.3, \mathrm{p}=0.0001$ adjusted by age, $\mathrm{OR}=4.70,95 \%$ $\mathrm{CI}=2.02-10.93, \mathrm{p}=0.0004$ adjusted by age and diabetes).

The laboratory parameters related to lipid profile (table 3) and blood sugar in all obese cases regarding their FTO rs9939609 gene polymorphic types shows laboratory parameters related to lipid profile and blood sugar in all obese cases regarding their FTO rs9939609 gene polymorphic types. Cases showed no significant difference for all values of lipid profile (cholesterols, triglycerides, HDL and LDL) as well as laboratory tests of diabetes (HbA1c, FBG, insulin and Homa IR) related to their polymorphic genotypes, also no significant BMI and WHR related to their polymorphic genotypes.

Table 3: Parameters related to lipid profile and blood sugar in all obese cases regarding their FT0 rs9939609 and rs1421085 gene polymorphism

\begin{tabular}{|c|c|c|c|c|c|c|c|c|c|c|}
\hline & \multicolumn{5}{|c|}{ rs9939609 } & \multicolumn{5}{|c|}{ rs1421085 } \\
\hline & Genotype & $\mathbf{N}$ & Mean & \pm SD & P (TT vs TA) & Genotype & $\mathbf{N}$ & Mean & \pm SD & P (TT vs TC) \\
\hline \multirow[t]{3}{*}{ Cholesterol } & $\mathrm{T} / \mathrm{T}$ & 24 & 206.92 & 43.411 & .955 & $\mathrm{~T} / \mathrm{T}$ & 35 & 200.17 & 39.212 & .941 \\
\hline & $\mathrm{T} / \mathrm{A}$ & 12 & 206.08 & 36.592 & & $\mathrm{~T} / \mathrm{C}$ & 39 & 199.51 & 37.572 & \\
\hline & $\mathrm{A} / \mathrm{A}$ & 14 & 190.71 & 43.187 & & $\mathrm{C} / \mathrm{C}$ & 31 & 209.61 & 55.143 & \\
\hline \multirow[t]{3}{*}{ Triglycerides } & $\mathrm{T} / \mathrm{T}$ & 24 & 155.29 & 53.179 & .435 & $\mathrm{~T} / \mathrm{T}$ & 35 & 144.46 & 58.506 & .723 \\
\hline & $\mathrm{T} / \mathrm{A}$ & 12 & 141.83 & 35.680 & & $\mathrm{~T} / \mathrm{C}$ & 39 & 139.92 & 51.175 & \\
\hline & $\mathrm{A} / \mathrm{A}$ & 14 & 152.93 & 47.671 & & $\mathrm{C} / \mathrm{C}$ & 31 & 126.02 & 46.085 & \\
\hline \multirow[t]{3}{*}{ HDL } & $\mathrm{T} / \mathrm{T}$ & 24 & 51.25 & 15.840 & .858 & $\mathrm{~T} / \mathrm{T}$ & 35 & 42.83 & 11.703 & .313 \\
\hline & $\mathrm{T} / \mathrm{A}$ & 12 & 50.33 & 10.790 & & $\mathrm{~T} / \mathrm{C}$ & 39 & 45.67 & 12.233 & \\
\hline & $\mathrm{A} / \mathrm{A}$ & 14 & 46.36 & 14.726 & & $\mathrm{C} / \mathrm{C}$ & 31 & 44.68 & 13.578 & \\
\hline \multirow[t]{3}{*}{ LDL } & $\mathrm{T} / \mathrm{T}$ & 24 & 126.46 & 41.455 & .391 & $\mathrm{~T} / \mathrm{T}$ & 35 & 137.03 & 53.139 & .542 \\
\hline & $\mathrm{T} / \mathrm{A}$ & 12 & 113.95 & 39.048 & & $\mathrm{~T} / \mathrm{C}$ & 39 & 130.55 & 37.144 & \\
\hline & $\mathrm{A} / \mathrm{A}$ & 14 & 117.64 & 36.679 & & $\mathrm{C} / \mathrm{C}$ & 31 & 134.13 & 35.808 & \\
\hline \multirow[t]{3}{*}{ HbA1c } & $\mathrm{T} / \mathrm{T}$ & 24 & 8.03 & 1.336 & .759 & $\mathrm{~T} / \mathrm{T}$ & 35 & 6.55 & 1.533 & .441 \\
\hline & $\mathrm{T} / \mathrm{A}$ & 12 & 8.18 & 1.557 & & $\mathrm{~T} / \mathrm{C}$ & 39 & 6.86 & 1.875 & \\
\hline & $\mathrm{A} / \mathrm{A}$ & 14 & 7.99 & 1.851 & & $\mathrm{C} / \mathrm{C}$ & 31 & 8.18 & 8.691 & \\
\hline \multirow[t]{3}{*}{ FBG } & $\mathrm{T} / \mathrm{T}$ & 24 & 139.50 & 15.795 & $.004^{*}$ & $\mathrm{~T} / \mathrm{T}$ & 35 & 117.03 & 31.831 & .291 \\
\hline & $\mathrm{T} / \mathrm{A}$ & 12 & 165.25 & 35.327 & & $\mathrm{~T} / \mathrm{C}$ & 39 & 124.97 & 32.360 & \\
\hline & $\mathrm{A} / \mathrm{A}$ & 14 & 142.64 & 25.040 & & $\mathrm{C} / \mathrm{C}$ & 31 & 115.19 & 32.252 & \\
\hline
\end{tabular}




\begin{tabular}{|c|c|c|c|c|c|c|c|c|c|c|}
\hline \multirow[t]{3}{*}{ Insulin } & $\mathrm{T} / \mathrm{T}$ & 24 & 20.45 & 4.949 & .093 & $\mathrm{~T} / \mathrm{T}$ & 35 & 23.47 & 4.915 & .091 \\
\hline & $\mathrm{T} / \mathrm{A}$ & 12 & 17.46 & 4.823 & & $\mathrm{~T} / \mathrm{C}$ & 39 & 21.67 & 4.114 & \\
\hline & $\mathrm{A} / \mathrm{A}$ & 14 & 21.21 & 4.598 & & $\mathrm{C} / \mathrm{C}$ & 31 & 22.10 & 4.826 & \\
\hline \multirow[t]{3}{*}{ Homa IR } & $\mathrm{T} / \mathrm{T}$ & 24 & 6.34 & 1.448 & .671 & $\mathrm{~T} / \mathrm{T}$ & 35 & 5.91 & 1.268 & .670 \\
\hline & $\mathrm{T} / \mathrm{A}$ & 12 & 6.14 & .898 & & $\mathrm{~T} / \mathrm{C}$ & 39 & 5.80 & .960 & \\
\hline & $\mathrm{A} / \mathrm{A}$ & 14 & 6.55 & 1.144 & & $\mathrm{C} / \mathrm{C}$ & 31 & 5.44 & 1.130 & \\
\hline \multirow[t]{3}{*}{ BMI } & $\mathrm{T} / \mathrm{T}$ & 24 & 43.54 & 4.850 & .984 & $\mathrm{~T} / \mathrm{T}$ & 35 & 40.52 & 3.632 & .228 \\
\hline & $\mathrm{T} / \mathrm{A}$ & 12 & 43.59 & 8.774 & & $\mathrm{~T} / \mathrm{C}$ & 39 & 41.67 & 4.408 & \\
\hline & $\mathrm{A} / \mathrm{A}$ & 14 & 43.06 & 3.595 & & $\mathrm{C} / \mathrm{C}$ & 31 & 42.93 & 8.452 & \\
\hline \multirow[t]{3}{*}{ WHR } & $\mathrm{T} / \mathrm{T}$ & 24 & .91 & .005 & .233 & $\mathrm{~T} / \mathrm{T}$ & 35 & .92 & .022 & .177 \\
\hline & $\mathrm{T} / \mathrm{A}$ & 12 & .91 & .008 & & $\mathrm{~T} / \mathrm{C}$ & 39 & .91 & .007 & \\
\hline & $\mathrm{A} / \mathrm{A}$ & 14 & .91 & .004 & & $\mathrm{C} / \mathrm{C}$ & 31 & .91 & .007 & \\
\hline
\end{tabular}

$\mathrm{N}=$ number of cases. Data presented mean \pm SD. ${ }^{*}=\mathrm{p}$-value.

The laboratory parameters related to lipid profile and blood sugar in all (table 3) obese diabetic cases regarding their FTO rs9939609 gene polymorphic type's shows laboratory parameters related to lipid profile and blood sugar in all obese diabetic cases regarding their FTO rs9939609 gene polymorphic types. Cases showed no significant difference for all values of lipid profile (cholesterols, triglycerides, HDL and LDL) as well as laboratory tests of diabetes (HbA1c, insulin and Homa IR) related to their polymorphic genotypes. Only the fasting blood glucose was significantly higher in the TA genotype than that of the TT genotype.

On the other hand, Laboratory parameters related to lipid profile and blood sugar in all obese cases regarding their FTO rs1421085 gene polymorphic types shows laboratory parameters related to lipid profile and blood sugar in all obese cases regarding their FTO rs1421085 gene polymorphic types. Cases showed no significant difference for all values of lipid profile (cholesterols, triglycerides, HDL and LDL) as well as laboratory tests of diabetes (HbA1c, FBG, insulin and Homa IR) related to their polymorphic genotypes.

Finally, the laboratory parameters related to lipid profile and blood sugar in all obese diabetic cases regarding their FTO rs1421085 gene polymorphic types shows laboratory parameters related to lipid profile and blood sugar in all obese diabetic cases regarding their FTO rs1421085 gene polymorphic types. Cases showed no significant difference for all values of lipid profile (cholesterols, triglycerides, HDL and LDL) as well as laboratory tests of diabetes (HbA1c, FBG, insulin and Homa IR) related to their polymorphic genotypes.

\section{DISCUSSION}

The first FTO polymorphisms associated with obesity were identified through a genome-wide association (GWA) study searching for novel genes associated with type-2 diabetes in diabetic cases and population controls from the Welcome Trust Case Control Consortium in the United Kingdom [23, 24]. Our study aims mainly to chock for the association of FTO gene rs 1421085 and rs 9939609 genes on obesity cases and diabetic obeses (T2DM) cases in Egyptian female.

In the first part of our study we have compared of FTO rs 9939609 polymorphic forms in total obese cases compared to controls and adjusted by age we showed significantly higher frequency of the AA genotype compared to controls $(\mathrm{p}=0.0001)$

Also, it is found a strong association in total obese cases compared to control adjusted by diabetes and age was showed significantly frequency of AA genotype compared with controls ( $p=0.012)$.

On the other hand, our study did not appear to influence any lipid parameter in the subject tested include (cholesterol, Trighcerds HDL and LDL) as well as laboratory tests of diabetes (HbA1C, FBG, insulin and Homa IR) in all obese cases of FTO rs 9939609 gene. Only rs FTO 9939609 gene showed fasting blood glucose was significantly higher in TT genotype than TA genotype, $\mathrm{p}=0.04 \%$ ). Therefore, our study reported that strong association of FTO rs 9939609 and T2DM. Also, there is no significant of BMI and WHR in this study of FTO rs 9939609 gene polymorphism in obases and obases diabetic case adjusted by age. Our data are in agreement with [25] reported that spatial analysis and meta-analysis showed an association between genetic polymorphism FTO 9939609 and T2DM. Also, showed that rs 9939609 was associated with T2DM risk somewhat independent BMI in East and South Asia population.

On the other hand, our study did not in agreement with Europe and the American population for FTO rs 9939609 polymorphism and there was an association between genetic polymorphism T2DM risks somewhat dependent BMI.

Our data showed not in agreement within the Chinese population [10] showed that FTO rs 9939609 genotype was not found to be associated with obesity overweight BMI, circumference or body fat. This is may be due to limited lifestyle or age.

Also, in adult Pakistan female population, [26] reported that association of rs 9939609 polymorphism variant of FTO gene in adult Pakistan female with BMI and obesity with measure of body fat distribution such as waist circumference, but our data in accordance with suggest the role of this polymorphism in fat deposition and predisposing factor for obesity, association of rs 9939609 variant of FTO gene with higher fasting blood sugar predispose to T2DM.

There was no increased risk of obesity in term of rs 9939609 polymorphism on their study on Cobort of Swedish men born 19201924 [27].

Additionally, [28] noted that the FTO rs 9939609 variant was associated with increase BMI adjusted for age beside Aalle of rs 9939609 polymorphism has been associated with increased risk to best-developing obesity.

Also, [29] note find an association of rs 9939609 with neither birth weight nor weight again in very low birth weight infant.

Our study similarly within Pakistan population Our study similarly [30] reported that FT09939609 gene is associated with obesity and showed for the first time in Pakistan with cornary artery disease to influence any lipid parameter in the subject tested, however, show a consistent association with blood glucose level. Therefore, it might play a role in progression to cornary artery disease through effecting plasma glucose metabolism.

This is according with a recent meta-analysis which reported that this variant has no correlation with serum lipid chemistry and is associated with glucose [31].

Other studies have found an interaction between the FTO rs 9939609 genotype and physical activity and reported that physically interactive homozygous risk. Allel carries has a $1.95 \pm 0.3 \mathrm{~kg} / \mathrm{m}^{2}$ increase in BMI compared with homozygous $\mathrm{T}$ allel and obesity. This is related to quantitative trails such as body weight waist circumference, fat mass was significantly with allel carrier [32].

On the other hand our data also noted by comparing of FTO rs 1421085 polymorphic forms in total obese cases compared to controls adjusted by diabetic and age. We showed significantly higher frequency of the CC genotype compared with controls $(\mathrm{p}<=$ $0.0001)$.

Also, all cases shown significantly higher frequency of $\mathrm{C}$ allel $(\mathrm{p}<0.00001)$ of FTO rs 1421085 polymorphic form in total cases compared to controls adjusted by diabetes and age was increase risk of obesity and T2DM BMI and WHR independently. 
Also, we have compared of lipid profile and blood sugar in all obeses cases to their FTO rs 1421085 polymorphic gene type. Our data showed parameter related to lipid profile there was no significant difference as well as testes of diabetes (HbAic, FBG, insulin and Homa IR).

Our studies showed no significant difference by comparing lipid profile and blood sugar in all obese diabetic cases to their FTO rs 1421085 gene polymorphism.

In addition to that our study found an association of FTO gene 1421085 polymorphism and high lights the possible role of obesity and DT2M type 2 diabetes and its correlation with higher fasting glucose independently from BMI and WHR on Egyptian female. This is may be due to limited lifestyle or age. The1421085 C allel was significantly associated with increase BMI was reported in Korean population [15].

Our data showed in agreement with Tunisian population [33] reported the association of FTO gene 1421085 polymorphism and high lights the possible role gene as a predictor of cardiovascular disease and T2DM and it correlation with higher fasting glucose independently from BMI. Other studies have shown in the Chinese population [34] say there no significant association between FTO variant of rs 1421085 genotype and obesity and level TC, TG, HDL and LDL were not found to be significantly associated with obesity.

Also, our data showed not agreement with European population, [11] reported that no significant association between FTO polymorphism includes 1421085 and BMI.

Our data also showed not in agreement with European population, [25] reported that spatial analysis showed studies on rs 1421085 in scarce and have limited regional coverage, lake of association due to smaller sample size and less studies.

There was no significant relationship has been reported between FTO gene polymorphism rs 9939609 and rs 1421085 and BMI in Turkey population [35], similarly rs 9939609 polymorphism and obesity was not associated with obesity [36].

Also, protuyuses children population, [37] found a significant association of rs9939609 and rs 1421085 polymorphism with weight, BMI, BMI 2-score waist circumference and hip circumference.

\section{CONCLUSION}

Finally, the present study was the first that reports the association of FTO gene polymorphism with obesity and T2DM and its correlation with higher fasting blood glucose also shown significant higher frequency of $\mathrm{C}$ allele which increases the risk of obesity. On the other hand, there was no significant correlation between genotype and obesity-related (anthropotemtric body composition) parameter.

The authors are glade to identify their contributions in the present work; Prof. Nassar A, was a principle investigator, research plan, supervision of the induction process and follow up steps of investigation and interpretation of final data. Also, Prof. Wafaa A was followed up results and had the supervision of Veterinary work and interpretation of final data. Finally, Prof. El Baz RA and EL ZEKRED AS were carried out the laboratory research investigations.

\section{AUTHORS CONTRIBUTIONS}

All the author have contributed equally

\section{CONFLICT OF INTERESTS}

\section{Declared none}

\section{REFERENCES}

1. Frayling TM, Timpson NJ, Weedon MN. A common variant in the FTO gene is associated with body mass index and predisposes to childhood and adult obesity. Science 2007;316:889-94.

2. Ai LL, Hui JX, Hong YX, Jun L, Jie Y, Jin SH, et al. Association between fat mass and obesity-associated (FTO) gene rs9939609 A/T polymorphism and polycystic ovary syndrome: a systematic review and meta-analysis. BMC Med Genet 2017;18:89.
3. Dina C, Meyre D, Gallina S, Durand E, Korner A, Jacobson P, et al. Variation in FTO contributes to childhood obesity and severe adult obesity. Nat Genet 2007;39:724-6.

4. Yang BL, Weixia LYL, Song M. Fto gene type and type 2 diabetes mellitus spatral analysis and meta-analysis. Gene 2017;8:7.

5. Gandhi M, Arivazhagan R, Sangeetha R, Swaminathan S. Association between insulin, ghrelin, homeostasis model assessment-insulin resistance, homeostasis model assessment$\beta$, waist-to-hip ratio and body mass index to plasma glucose and glycosylated hemoglobin and its clinical usefulness in type 2 diabetes mellitus patients with obesity. Asian J Pharm Clin Res 2010;10:287-29.

6. Finucane MM, Stevens GA, Cowan MJ. National, regional, and global trends in body-mass index since 1980: systematic analysis of health examination surveys and epidemiological studies with 960 country-years and 9.1 million participants. Lancet 2011;377:557-67.

7. Varun KS, Krc R. Echo of lodhradi kashaya in lipid profile of type 2 diabetes mellitus patients. Asian J Pharm Clin Res 2017;10:309-12.

8. Chang SH, Pollack LM, Colditz GA. Life years lost associated with obesity-related diseases for $u$. s. non-smoking adults. PLoS One 2013;18:8-e66550.

9. Wabitsch M, Moss A. Kromeyer-Hauschild K. Unexpected plateauing of childhood obesity rates in developed countries. BMC Med 2014;10:1186-41.

10. Li H, Wu Y, Loos RJ. Variations in the fat mass and obesityassociated (FTO) gene are not associated with obesity in a Chinese Han population. Diabetes 2008;57:264-8.

11. OhashiJ, NakaI, Kimura R. FTO polymorphisms in oceanic populations. J Human Genetics 2007;52:1031-5.

12. Hennig BJ, Fulford AJ, Sirugo G. FTO gene variation and measures of body mass in an African population. BMC Medical Genetics 2009;10:21.

13. Chang YC, Liu PH, Lee WJ. Common variation in the fat mass and obesity-associated (FTO) gene confers risk of obesity and modulates BMI in the Chinese population. Diabetes 2008;57:2245-52.

14. Fang H, Li Y, Du S. Variant rs9939609 in the FTO gene is associated with body mass index among Chinese children. BMC Medical Genetics 2010;11:136.

15. Cha SW, Choi SM, Kim KS. Replication of genetic effect of FTO polymorphisms on BMI in a Korean population. Obesity 2008;16:2187-9.

16. Tan JT, Dorajoo R, Seielstad M. FTO variants are associated with obesity in the Chinese and malay populations in singapore. Diabetes 2008;57:2851-7.

17. Li M, Liu Y, Xu P, Ye M, Liu Y. Association of the rs9939609 polymorphism of FTO gene with overweight or obesity in Hazakh children. Chinese J Med Genetics 2010;27:678-81.

18. Sun Y, Sun J, Wang X, You W, Yang M. Variants in the fat mass and obesity-associated (FTO) gene are associated with obesity and C-reactive protein levels in Chinese Han populations. Clin Invest Med 2010;33:E405-12.

19. Xi B, Shen Y, Zhang M. The common rs9939609 variant of the fat mass and obesity-associated gene is associated with obesity risk in children and adolescents of Beijing, China. BMC Med Genetics 2010;11:107.

20. Yajnik CS, Janipalli CS, Bhaskar S. FTO gene variants are strongly associated with type 2 diabetes in South Asian Indians. Diabetologia 2009;52:247-52.

21. World Health Organization. "Measuring obesity classification and description of anthropometric data," Report on a WHO Consultation of the Epidemiology of Obesity, WHO, Warsaw, Poland; 1987.

22. Matthews DR, Hosker JP, Rudenski AS, Naylor BA, Treacher DF, Turner RC. Homeostasis model assessment: Insulin resistance and $\beta$-cell function from fasting plasma glucose and insulin concentrations in man. Diabetologia 1985;28:412-9.

23. Frayling TM, Timpson NJ, Weedon MN. A common variant in the FTO gene is associated with body mass index and predisposes to childhood and adult obesity. Science 2007;316:889-94. 
24. Claussnitzer S, Pankel KH, Gevald Q, Wouter M, Christine $\mathrm{H}$, Viktovial G, et al. FTO obesity variant civcuitry and dipocyte Browing in Humen N. Englaned 2015;373:895-907.

25. Yang BL, Weixia LYL, Song M. FTO gene type and type 2 diabetes mellitus spatral analysis and meta analysis. Gene 2017;8:7.

26. Shahid S, Shalid S, Muhammed I, Nasir A, Saqib M. Common variant of Fto gene rs 9939609 and obesity. Biomed Res Intern 2013;324093:7.

27. Jacobsson JA, Riserus U, Axelsson T. The common FTO variant rs9939609 is not associated with BMI in a longitudinal study on a cobort of swedish men born 1920-1924. BMC Med Genet 2009;10:131.

28. Samaan Z, Anand S, Zhang X. The protective effect of the obesity-associated rs9939609A variant in fat mass and obesity associated gene on depression. Mol Psychiatry 2012;10:160

29. Haller S, Spiegler J, Hemmelmann C. Polymorphisms in FTO and MAF genes and birth weight, BMI, Ponderal index; 2013.

30. Shahid S, Abdul Rehman S, Shahida H. Role of common variant of fa $t$ mass and obesity associated (Fto) gene in obesity and coronary artery disease. Lipid Health Disease 2016;15:29.
31. Liu Y, Liu Z, Song Y. Meta-analysis added power to identify variants in FTO associated with type 2 diabets and obesity in the Asian population. Obesity 2010;18:1619-24.

32. Kopelman P. Health risks associated with overweight and obesity. Obes Rev 2007;1:13-7.

33. Elouej S, Nagara M, Attuaua R, Sallem O, Rejeb I, Hosmuma S, et al. Association of genetic variant in Ftogene. J Diabetes Complications 2016;30:206-11.

34. Wang Ya, Yanxiong L, Xuenin Z, Zhen Z, Jianru W, Beiwang L. Variant rs 1421085 in Fto gene contribute childhood obesity inchinase children. Obesity Rea Search Practices 2013;7e:14-22.

35. Solak M, Ozdemir E, Saliha HY, Kaganucok S, Evrimsuna AT, Ahmet B. Association of obesity with rs 1421085 and rs 9939609 polymorphism of Fto gene. Mol Bio Rep 2014;41:7331-86.

36. Hinney A, Vogel CIG, Hebebrand $\mathrm{j}$ from monogenic to polygenic obesity: recent advances. Eur Child Adolesc Psychiatry 2010;19:297-10.

37. Albuquerque D, Nobrega C, Manco L. Association of FTO polymorphisms with obesity and obesity related outcomes in portuguese children. PLoS One 2013;8:e54370. 